Article

\title{
Mercury(II) Removal with Modified Magnetic Chitosan Adsorbents
}

\section{George Z. Kyzas ${ }^{1,2, *}$ and Eleni A. Deliyanni ${ }^{1}$}

1 Department of Chemistry, Aristotle University of Thessaloniki, Thessaloniki GR-541 24, Greece; E-Mail: lenadj@chem.auth.gr

2 Department of Petroleum and Natural Gas Technology, Technological Educational Institute of Kavala, Kavala GR-654 04, Greece

* Author to whom correspondence should be addressed; E-Mail: georgekyzas@gmail.com; Tel./Fax: +30-2310-858607.

Received: 6 April 2013; in revised form: 15 May 2013 / Accepted: 20 May 2013 /

Published: 24 May 2013

\begin{abstract}
Two modified chitosan derivatives were prepared in order to compare their adsorption properties for $\mathrm{Hg}(\mathrm{II})$ removal from aqueous solutions. The one chitosan adsorbent (CS) is only cross-linked with glutaraldehyde, while the other (CSm), which is magnetic, is cross-linked with glutaraldehyde and functionalized with magnetic nanoparticles $\left(\mathrm{Fe}_{3} \mathrm{O}_{4}\right)$. Many possible interactions between materials and $\mathrm{Hg}$ (II) were observed after adsorption and explained via characterization with various techniques (SEM/EDAX, FTIR, XRD, DTG, DTA, VSM, swelling tests). The adsorption evaluation was done studying various parameters as the effect of $\mathrm{pH}$ (optimum value 5 for adsorption and 2 for desorption), contact time (fitting to pseudo-first, -second order and Elovich equations), temperature (isotherms at $25,45,65^{\circ} \mathrm{C}$ ), in line with a brief thermodynamic analysis $\left(\Delta \mathrm{G}^{0}<0, \Delta \mathrm{H}^{0}>0, \Delta \mathrm{S}^{0}>0\right)$. The maximum adsorption capacity (fitting with Langmuir and Freundlich model) of CS and CSm at $25{ }^{\circ} \mathrm{C}$ was 145 and $152 \mathrm{mg} / \mathrm{g}$, respectively. The reuse ability of the adsorbents prepared was confirmed with sequential cycles of adsorption-desorption.
\end{abstract}

Keywords: magnetic chitosan; cross-linking; mercury(II); adsorption 


\section{Introduction}

Chitosan (poly- $\beta-(1 \rightarrow 4)-2-$ amino-2-deoxy-D-glucose) is an aminopolysaccharide and cationic polymer produced by the $\mathrm{N}$-deacetylation of chitin. It is one of the most naturally abundant and cheap biopolymers. It is a hydrophilic, nontoxic, biodegradable, and biocompatible material with the ability to form complexes with metals [1-3]. The latter could be easily explained by the presence of amino groups on the polymer matrix, which can interact with metal ions of the solution by ion exchange or other complexation reactions (mainly chelation) [4,5]. The high content of amino groups also makes possible many chemical modifications on the polymer with the purpose of improving its adsorption features, such as selectivity and adsorption capacity [6,7]. Its adsorption performance can be further improved by cross-linking with reagents such as glutaraldehyde, tripolyphosphate salts, epichlorohydrin, ethylene glycol or diglycidyl ether, which can stabilize chitosan in acid solutions and increase its mechanical properties [8].

Chitosan has been repeatedly characterized as a metal superadsorbent [Cu(II), $\mathrm{Cd}(\mathrm{II}), \mathrm{Pb}(\mathrm{II}), \mathrm{Ni}(\mathrm{II})$, $\mathrm{Hg}(\mathrm{II}), \mathrm{Cr}(\mathrm{VI}), \mathrm{U}(\mathrm{VI}), \mathrm{Mo}(\mathrm{V}), \mathrm{V}(\mathrm{V}), \mathrm{Pd}(\mathrm{II}), \mathrm{Pt}(\mathrm{IV}), \mathrm{Au}(\mathrm{III}), \mathrm{As}(\mathrm{V}), \mathrm{Se}(\mathrm{V})]$ presenting significantly high adsorption capacities $(0.2-8.0 \mathrm{mmol} / \mathrm{g})$ [4,9]. Their maximum adsorption capacity is varied, which is attributed to: (i) the form of chitosan (beads, powder), (ii) the possible chemical modifications (cross-linking, grafting reactions), (iii) the different experimental conditions ( $\mathrm{pH}$, particle size, conditioning, and composition of the solution), which are not systematically the same [4]. The latter is the reason why the direct comparison of experimental data is not possible.

In the present study, $\mathrm{Hg}$ (II) was selected as target for removal with adsorption technique, which is considered to be one of the most effective and economical treatment methods for metal removal in the general field of separation processes of chemical technology $[4,9,10]$. In general, contamination of aquatic systems is a serious environmental problem given the pollution of natural waters by heavy metal ions is one of the main sources all over the World. Mercury is one of the most toxic heavy metals since it is not biodegradable and causes a lot of toxic effects in the human body [11]. Its presence is due to a combination of natural processes (volcanic action, erosion of mercury-containing sediments) and anthropogenic activities (mining operations, tanneries, metal plating facilities) as well [12]. Although numerous works have been published aiming the removal of various metals (or especially $\mathrm{Hg}(\mathrm{II})$ [13-16]) with adsorption onto chitosan materials [4,9], a great of importance is the modification of chitosan (apart from the common chitosan derivatives grafted with carboxyl, amino, amido, imino, sulfonate, etc. [17-21]) with magnetic nanoparticles in order to form a magnetic chitosan derivative. Some magnetically modified chitosans were already tested for the removal of many metals in literature [22-25]. However, there is lack of studied for the use of magnetic chitosan powders (not resins or membranes) as adsorbent for mercury(II) removal [26,27].

In the current study, a modification of pure chitosan was realized to form two differently modified derivatives: (i) cross-linked with glutaraldehyde (denoted as CS), and (ii) cross-linked with glutaraldehyde and functionalized with magnetic nanoparticles (denoted as CSm). Many possible interactions between materials and $\mathrm{Hg}$ (II) were observed after adsorption and explained via characterization with various techniques (SEM/EDAX, FTIR, XRD, DTG, DTA, VSM, swelling tests). The adsorption evaluation was done studying various parameters as the effect of $\mathrm{pH}$, contact time, temperature, in line with a brief thermodynamic analysis. The reusability of the adsorbents 
prepared was confirmed with sequential cycles of adsorption-desorption, given the technological field of this study.

\section{Results and Discussion}

\subsection{Characterization}

It is well-known that chitosan derivatives present high swelling percentages [28]. The swelling percentage was found to be $46 \%$ for CSm and a little bit higher (54\%) for CS. Therefore, given the initial mass of adsorbent used was adjusted to $0.02 \mathrm{~g}$, the calculated water content was $0.0092 \mathrm{~g}$ for CS and $0.0108 \mathrm{~g}$ for $\mathrm{CSm}$. The slight increase can be due to the absence of functionalized magnetic nanoparticles on CSm, which gave a more compact structure on the magnetic derivative. In addition, the kinetics of swelling (Figure 1) revealed the similar behavior of two chitosans (CS and CSm). There is a steep ascent within $1 \mathrm{~h}$ being succeeded by a more gradual rise for both adsorbents. After $200 \mathrm{~min}$, the swelling of water seemed to be completed (equilibrium stage).

Figure 1. Effect of contact time on swelling percentage.

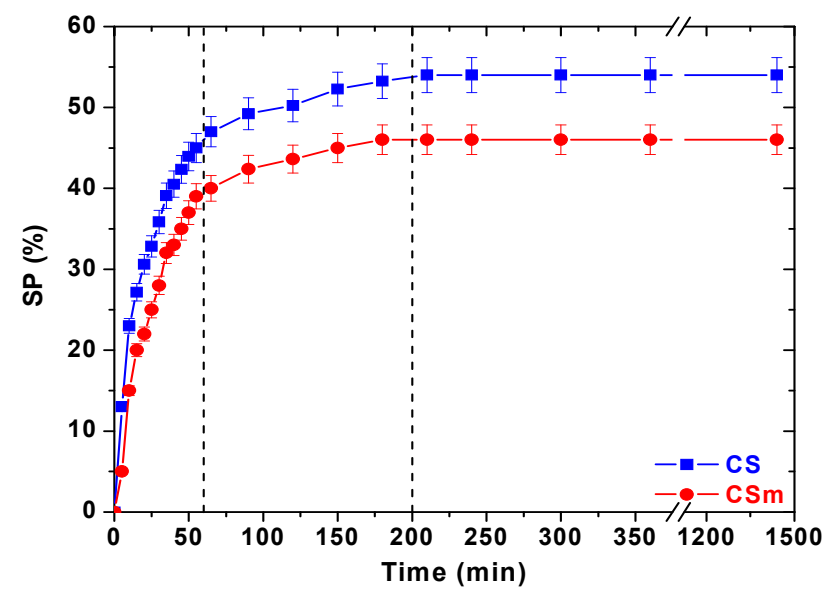

The XRD patterns of CS and of CSm are shown in Figure 2. In the X-ray diffraction spectrogram of CS, a broad peak at $2 \theta=20.2^{\circ}$ is presented due to the amorphous state of chitosan. In the spectrogram for the magnetic sample $(\mathrm{CSm})$, the six characteristic peaks of $\mathrm{Fe}_{3} \mathrm{O}_{4}$ at $2 \theta=30.1^{\circ}, 35.5^{\circ}$, $43.3^{\circ}, 53.4^{\circ}, 57.2^{\circ}$, and $62.5^{\circ}$, attributable to the indices (220), (311), (400), (422), (511), and (440), respectively, were observed. They were indexed using the Joint Committee on Power Diffraction Standards database (File No. 19-0629) to $\mathrm{Fe}_{3} \mathrm{O}_{4}$ with a cubic inverse spinel structure, indicating the presence of magnetite particles [29]. The results showed that chitosan binding did not result in a phase change in the structure of the magnetic nanoparticles. The average crystallite size, D (nm), of magnetite was calculated about $10.5 \mathrm{~nm}$, using the Debye-Scherrer equation [30]:

$$
\mathrm{D}=\frac{\mathrm{K}_{\mathrm{s}} \cdot \lambda}{\mathrm{B} \cdot \cos \theta}
$$

where $K_{s}$ is a constant $\left(K_{s}=0.9\right.$ for CuKa), $\lambda(n m)$ is wavelength $(0.15405 \mathrm{~nm}$ for CuKa), B is the peak width of half-maximum (rad) and $\theta$ is the diffraction angle. The patterns of CSm also exhibited a broad peak at $2 \theta=20.3^{\circ}$ due to the presence of chitosan. 
Figure 2. X-ray diffraction (XRD) patterns of CS and CSm.

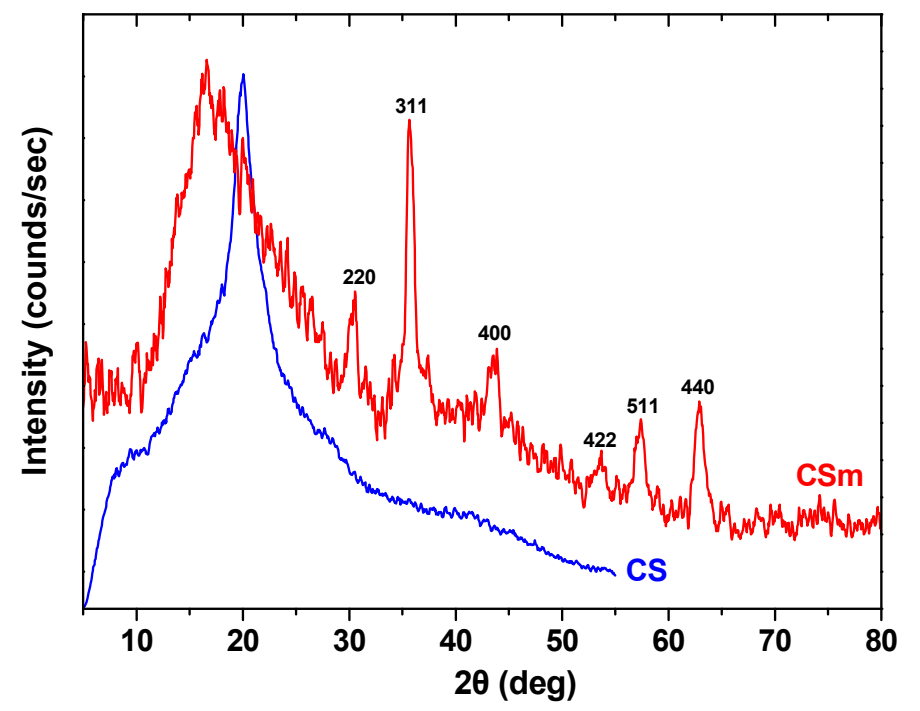

SEM analysis provided information about the size and the surface morphology of magnetic chitosan. The SEM image of CSm (Figure 3) shows that it had a spherical shape and the final products presented aggregation. It is concluded that chitosan was immobilized on the surface of $\mathrm{Fe}_{3} \mathrm{O}_{4}$ particles with a core-shell construction of an average diameter about $1 \mu \mathrm{m}$. The map images (Figure 3b) present a confirmation of the success of the chitosan coating process on the surface of $\mathrm{Fe}_{3} \mathrm{O}_{4}$ particles with a good distribution. EDX analysis determined the chemical composition of the CSm. The elemental percentage of carbon was found to be $52.30 \%$, while the respective of oxygen was $22.44 \%$ and $25.36 \%$ of iron.

Figure 3. SEM images of: (a) CS; (b) CSm; (c) Fe distribution map of CSm.

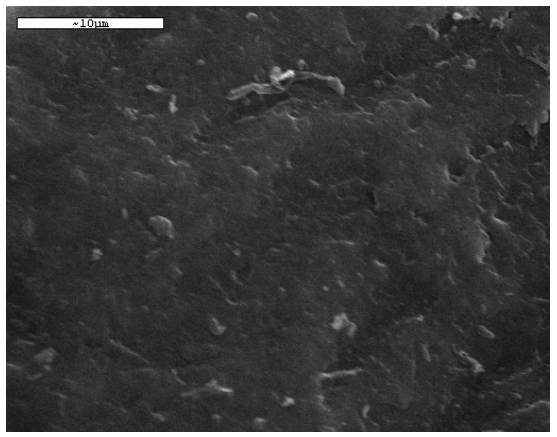

(a)

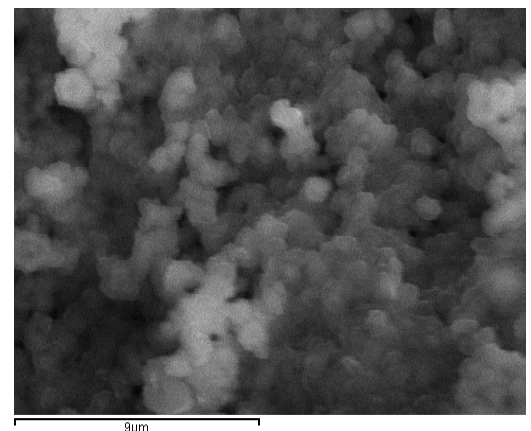

(b)

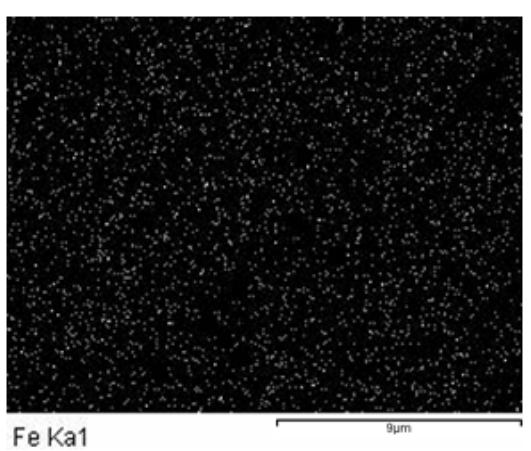

(c)

The magnetic property was measured on a vibrating sample magnetometer (VSM) and presented via VSM plot. According to Figure 4, the VSM plot showed a value of $5.79 \mathrm{emu} / \mathrm{g}$ for the saturation magnetization of CSm. This value is far less than that reported for pure magnetite colloidal nanocrystals $(36.941 \mathrm{emu} / \mathrm{g}$ ) [31], but it may be due to the rather small size and the relatively low amount of $\mathrm{Fe}_{3} \mathrm{O}_{4}$ loaded on $\mathrm{CSm}$. In any case, the magnetic property remained high enough for a magnetic separation to be achieved. Because of the presence of magnetic particles, using an external magnetic field, CSm could be easily and rapidly separated from the aqueous solution after the 
experiments. In the inset of Figure 4, the right vial contains an aqueous solution of $\mathrm{Hg}(\mathrm{II})$ after adsorption onto $\mathrm{CS}$, whereas the left vial contains an aqueous solution of $\mathrm{Hg}$ (II) after adsorption onto CSm. In the presence of an external magnetic field, the black particles of the CSm were attracted to the wall of the vial to emphasize the magnetism of the prepared CSm. So, a brief comparative table (Table 1) presents the differences of the main physical properties of chitosan adsorbents prepared.

Figure 4. VSM plot of CSm (Inset: photo of CS and CSm after Hg(II) adsorption).

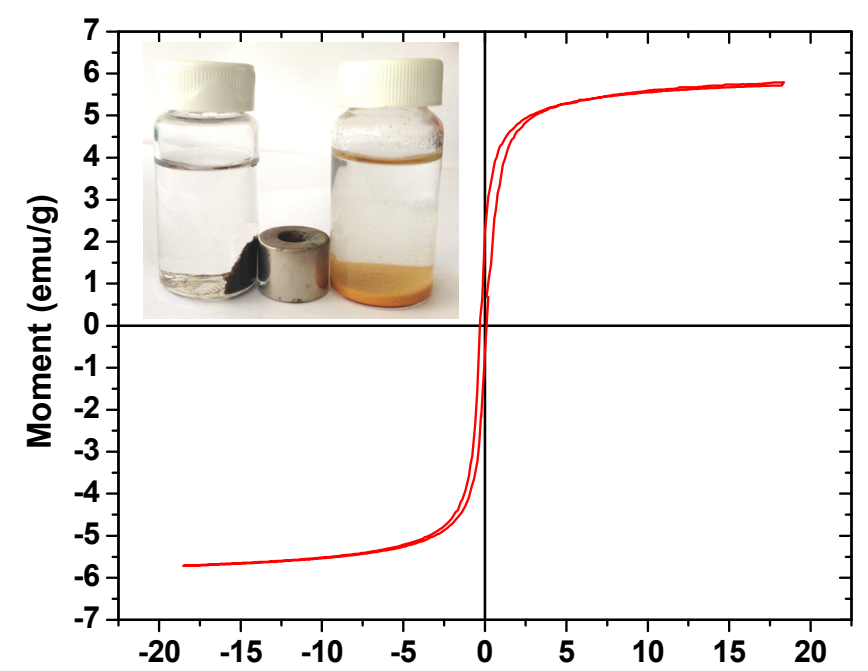

Table 1. Properties of the adsorbents.

\begin{tabular}{ccc}
\hline \multirow{2}{*}{$\begin{array}{c}\text { Property } \\
\text { Type }\end{array}$} & \multicolumn{2}{c}{ Adsorbent } \\
\cline { 2 - 3 } powder & $\begin{array}{c}\text { CSm } \\
\text { powder }\end{array}$ \\
\hline SP $(\%)$ & 54 & 46 \\
Water content $(\mathrm{g})$ & 0.0092 & 0.0108 \\
Particle size $(\mu \mathrm{m})$ & $75-125$ & $75-125$ \\
Surface area $\left(\mathrm{m}^{2} / \mathrm{g}\right)$ & $<3$ & $<3$ \\
Porosity & non-porous & non-porous \\
Magnetization $(\mathrm{emu} / \mathrm{g})$ & - & 5.79 \\
Iron $(\%)$ & - & 25.36 \\
\hline
\end{tabular}

Differences in the chemistry of the surfaces are presented on differential thermal gravimetric (DTG) curves measured in nitrogen (Figure 5), where the peaks represent weight loss at the specific temperature range. The first peak centered at about $80-100{ }^{\circ} \mathrm{C}$ for $\mathrm{CS}$ and $\mathrm{CSm}$, in correlation to the endothermic effect on the differential thermal analysis (DTA) curves presented in the inset of Figure 5, can be linked to weight loss due to the evaporation of physically adsorbed water. In the case of CS, that peak presented a maxima at $100{ }^{\circ} \mathrm{C}$, while a second peak with a higher mass loss was found at $400{ }^{\circ} \mathrm{C}$, caused by the decomposition of CS derivatives containing hydroxyl and amino groups [32]. CSm displayed a broad exothermic peak around $270{ }^{\circ} \mathrm{C}$ that can be attributed to the decomposition of chitosan while the weight loss in the range 450-500 ${ }^{\circ} \mathrm{C}$ should be assigned to the further decomposition of chitosan residues, whereas the band in the range of $600-900{ }^{\circ} \mathrm{C}$ can be attributed to the reduction of $\mathrm{Fe}_{3} \mathrm{O}_{4}$ by reaction with residual carbon [29]. 
Figure 5. Differential thermogravimetry (DTG) curves in nitrogen (inset: differential thermal analysis (DTA) curves in nitrogen).

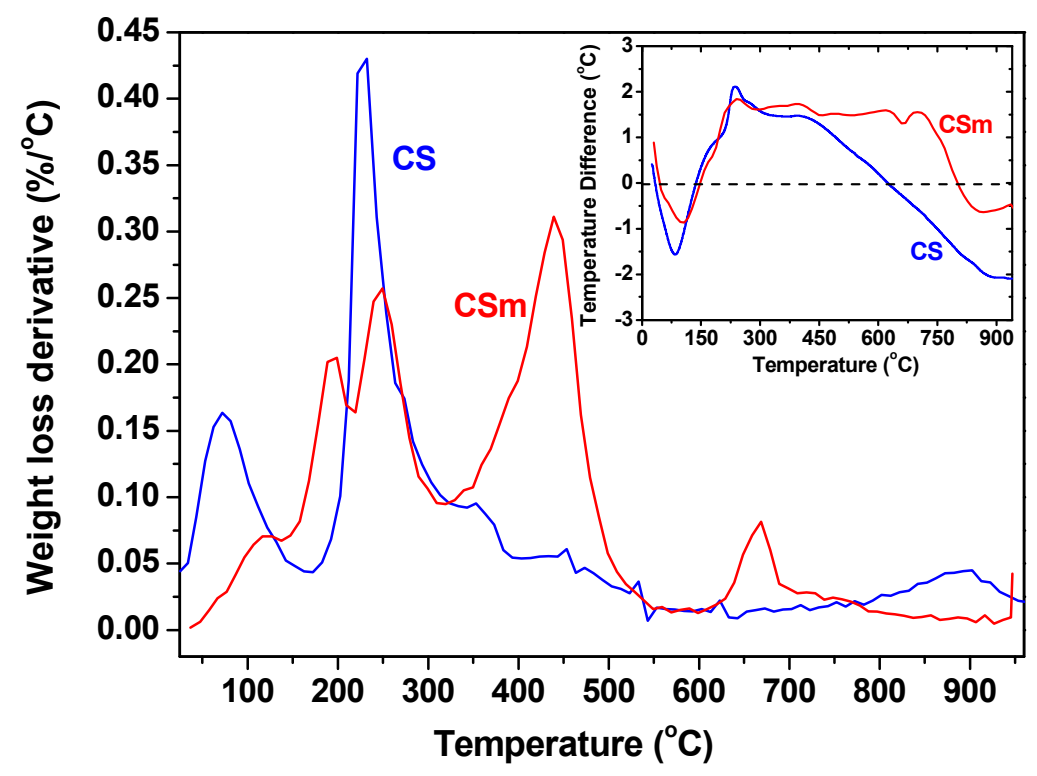

FTIR spectra (Figure 6) revealed the differences in the chemical features of the raw materials, as well as for the materials after adsorption. In the spectrum of CS a strong peak around 3,400 $\mathrm{cm}^{-1}$ was appeared, due to the stretching vibration of $\mathrm{O}-\mathrm{H}$, the extension vibration of $\mathrm{N}-\mathrm{H}$ and the interhydrogen bonds of the polysaccharide [33]. The $\mathrm{C}-\mathrm{H}$ stretching vibration of the polymer backbone is manifested through strong peak at 2,922 $\mathrm{cm}^{-1}$ while the two characteristic bands centered at 1,627 and $1,501 \mathrm{~cm}^{-1}\left(1,520 \mathrm{~cm}^{-1}\right.$ for CSm) can be attributed to the $\mathrm{C}=\mathrm{O}$ stretching vibration mode of NHCO (amide I) along with an $\mathrm{N}-\mathrm{H}$ deformation mode and the $\mathrm{N}-\mathrm{H}$ bending of $\mathrm{NH}_{2}$ group, respectively [20]. The band at $1,217 \mathrm{~cm}^{-1}$ can be attributed to $\mathrm{C}-\mathrm{N}$ stretching vibration (amino group band) and the band at $1,096 \mathrm{~cm}^{-1}$ to the stretching vibration mode of the hydroxyl group. Characteristic bands of chitosan appeared at $1,131 \mathrm{~cm}^{-1}$ due to the special broad peak of (1-4)-glucosidic band in polysaccharide unit, at $1,028 \mathrm{~cm}^{-1}$ due to the stretching vibration of $\mathrm{C}-\mathrm{O}-\mathrm{C}$ in the glucose circle, and at the $1,060-1,015 \mathrm{~cm}^{-1}$ corresponding to $\mathrm{CH}-\mathrm{OH}$ in cyclic compounds [20]. In the spectrum of $\mathrm{CSm}$, in addition to the characteristic absorption bands of the functional groups of chitosan, a new peak appeared at $570 \mathrm{~cm}^{-1}$, related to $\mathrm{Fe}-\mathrm{O}$ group, demonstrating that $\mathrm{CS}$ was coated successfully to the magnetic $\mathrm{Fe}_{3} \mathrm{O}_{4}$ nanoparticles via electrostatic interaction, results consistent to the core-shell SEM images. The surface of iron oxide possessed negative charges having this way an affinity toward CS, so, the protonated CS could coat the magnetite nanoparticles by the electrostatic interaction and chemical reaction through glutaraldehyde cross-linking $[34,35]$. 
Figure 6. FTIR spectra of CS and CSm before and after $\mathrm{Hg}(\mathrm{II})$ adsorption.

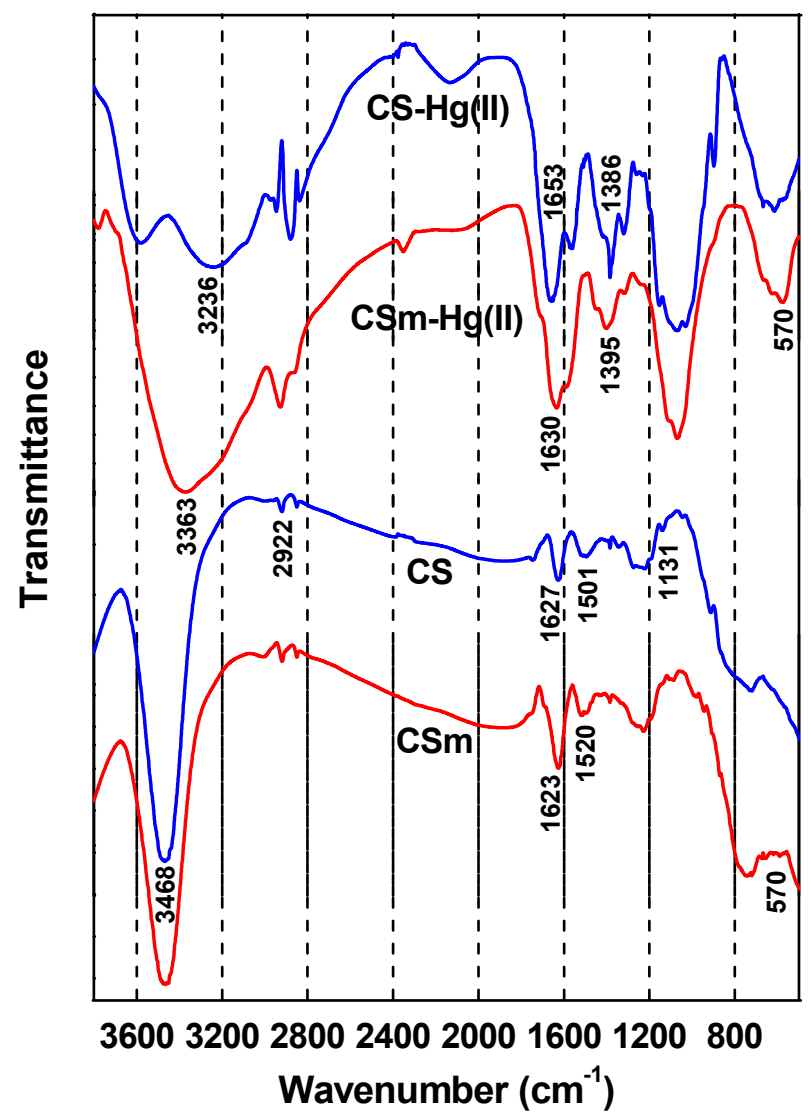

In the spectra of $\mathrm{CS}-\mathrm{Hg}(\mathrm{II})$ and $\mathrm{CSm}-\mathrm{Hg}(\mathrm{II})$, the interactions were mainly affirmed by the reduction of the intensity of the peak assigned to the $-\mathrm{NH}$ group in amine, confirming that nitrogen atoms are the main adsorption sites for $\mathrm{Hg}$ (II) adsorption on CS and CSm. It is well known that nitrogen-ligand possesses affinity to adsorb $\mathrm{Hg}(\mathrm{II})$, which belongs to soft acid [36] leading to the mercury chelation with nitrogen atoms of amino groups [37-40]. On the other hand, the peaks at 1627 and $1,623 \mathrm{~cm}^{-1}$ for $\mathrm{CS}$ and $\mathrm{CSm}$, characteristic peak of $-\mathrm{NHCO}$, shift to 1,653 and $1,630 \mathrm{~cm}^{-1}$ respectively, evidence of the coordination of -NHCO with $\mathrm{Hg}$ (II). It is also observed that, after $\mathrm{Hg}$ (II) sorption, appeared a new band at $1,386 \mathrm{~cm}^{-1}[\mathrm{CS}-\mathrm{Hg}(\mathrm{II})]$ and $1,395 \mathrm{~cm}^{-1}[\mathrm{CSm}-\mathrm{Hg}(\mathrm{II})]$, attributed to $\mathrm{C}-\mathrm{N}$ stretching vibration [40]. The presence of this peak indicated that even after cross-linking, the structure resulting from the primary amino and glutaraldehyde reaction (imine bond) is also capable of adsorbing metallic cations [41]. This may be attributed to the presence of free lone pair of electrons on nitrogen atoms at $\mathrm{pH} 5.0$, suitable for coordination with the metal ion to give the corresponding magnetic chitosan-metal complex [42]. In addition, the peak at $3,468 \mathrm{~cm}^{-1}$ corresponding to the stretching vibration of $\mathrm{OH}$-groups shifts to $3,236 \mathrm{~cm}^{-1}$ [CS-Hg(II)] and 3,363 $\mathrm{cm}^{-1}$ [CSm-Hg(II)] after $\mathrm{Hg}(\mathrm{II})$ sorption, indicating that $-\mathrm{OH}$ groups also take part in sorption. This conclusion was consistent with other studies for other metel ions. Li and Bai [43] showed that the binding of lead ions to nitrogen atom in chitosan and oxygen atom in - $\mathrm{OH}$ group may contribute to lead adsorption on chitosan/PVA beads. Other studies also found that $-\mathrm{OH}$ and $-\mathrm{NH}_{2}$ was involved in adsorption process $[40,44]$. Furthermore, despite the bonds of GLA with amino groups of chitosan (after the 
formation of CS or CSm), there are still free amino groups able to interact (proposed chelation reaction of Figure 7). The proposed chelated structures of $\mathrm{Hg}(\mathrm{II})$ with CS and CSm is presented in Figure 7.

Figure 7. Preparation of CS and CSm and possible interaction with $\mathrm{Hg}(\mathrm{II})$.

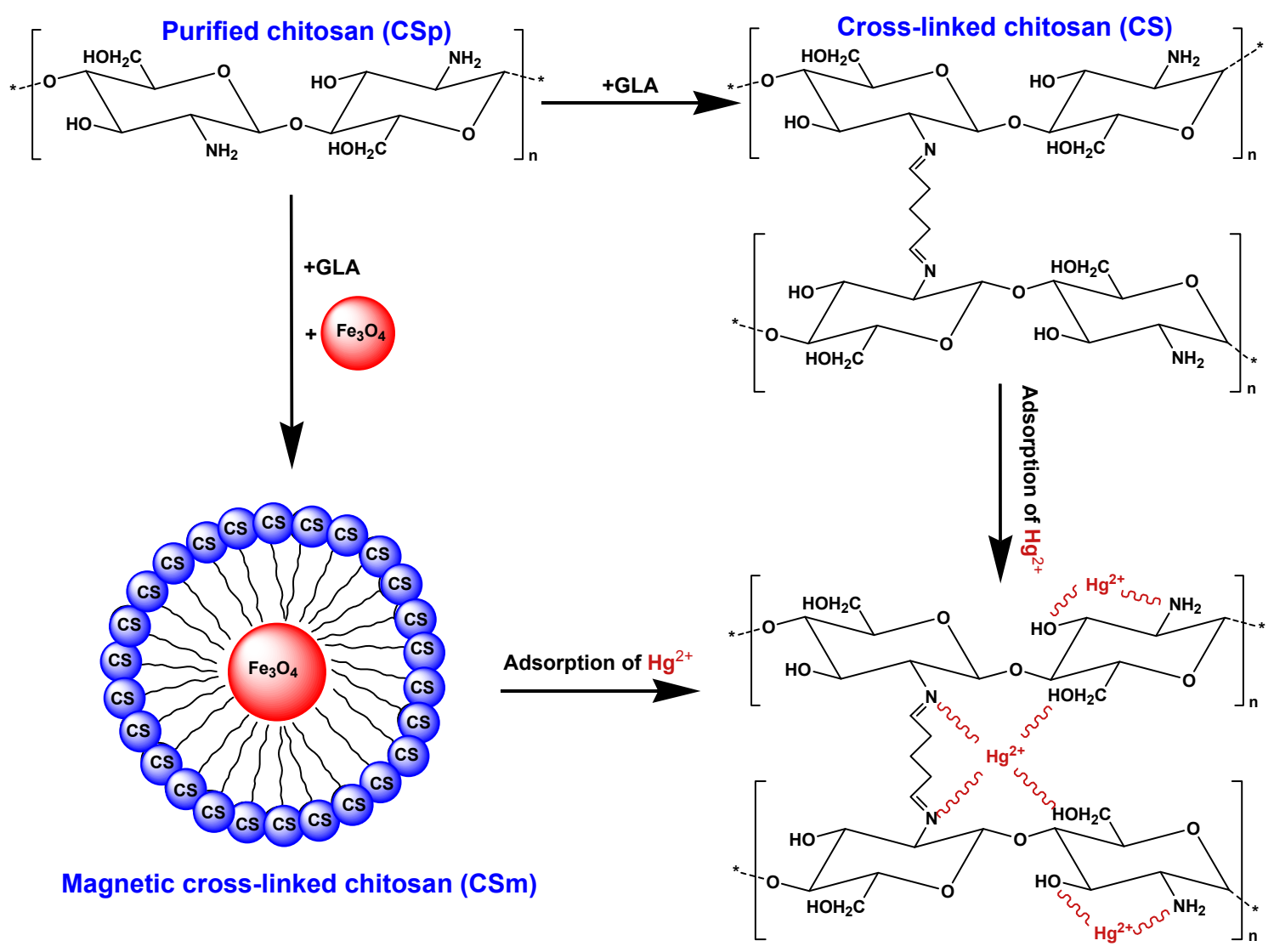

\subsection{Adsorption}

\subsubsection{Effect of $\mathrm{pH}$}

The effect of $\mathrm{pH}$ was revealed a similar behavior for CS and CSm. As presented in Figure 8, at $\mathrm{pH}=2$ both adsorbents presented their lowest $\mathrm{Hg}(\mathrm{II})$ uptake $(25 \%$ and $29 \%$ for CS and CSm, respectively), while at $\mathrm{pH}=3$ the respective values were $34 \%$ and $44 \%$, so a change of $9 \%$ and $15 \%$ was observed. Reaching in less acidic $\mathrm{pH}$ conditions $(\mathrm{pH}=4)$, the metal uptake was further increased to $45 \%$ and $54 \%$ for for $\mathrm{CS}$ and $\mathrm{CSm}$, respectively. At $\mathrm{pH}=5$ and $\mathrm{pH}=6$, the metal uptakes were stabilized to $56 \%$ and $57 \%$ for CS and $58 \%$ and $60 \%$ for CSm. Higher $\mathrm{pH}$ values were not studied in order to avoid precipitation. At a first glance, both adsorbents presented similar trend in their metal uptake increase, but in any case CSm showed a slight superiority in metal uptake than CS. According to the above experimental findings, the optimum $\mathrm{pH}$ found was 5 for both materials. This may be attributed to the presence of free lone pair of electrons on nitrogen atoms of chitosan suitable for coordination with the metal ion to give the corresponding chitosan-metal complex (Figure 7). It is selected to avoid the value of $\mathrm{pH}=6$, which is near to the crucial zone of precipitation, where the metal ions get out of the solution due to formation of colloidal precipitate of $\mathrm{Hg}(\mathrm{OH})_{2}$ and not due to the adsorption of free $\mathrm{Hg}(\mathrm{II})$ ions [26]. In general the uptake of $\mathrm{Hg}$ (II) at $\mathrm{pH}>6$ is attributed to the formation of metal hydroxide species such as soluble $\mathrm{Hg}(\mathrm{OH})^{+}$and/or insoluble precipitate of 
$\mathrm{Hg}(\mathrm{OH})_{2}$. Furthermore, a brief comment can be done about the change of values between the initial (adjusted) $\mathrm{pH}$ of solution and the final [after $\mathrm{Hg}$ (II) adsorption] (inset of Figure 8). At the optimum/studied $\mathrm{pH}$ value (5), the $\mathrm{pH}$ change was 0.42 for $\mathrm{CS}$ and 0.21 for CSm. So, the slight change can be easily ignored. The latter was a strong reason for not adjusting the $\mathrm{pH}$ value during adsorption (continuously), preferring a free- $\mathrm{pH}$ process. In this way, the adsorption did not direct to fixed adsorption paths (with possible additions of $\mathrm{H}^{+}$or $\mathrm{OH}^{-}$in the case of continuous $\mathrm{pH}$-adjustment), but govern only by the interactions with $\mathrm{Hg}(\mathrm{II})$.

Figure 8. Effect of $\mathrm{pH}$ on adsorption (Inset: Change of $\mathrm{pH}$ between initial/adjusted conditions and final).

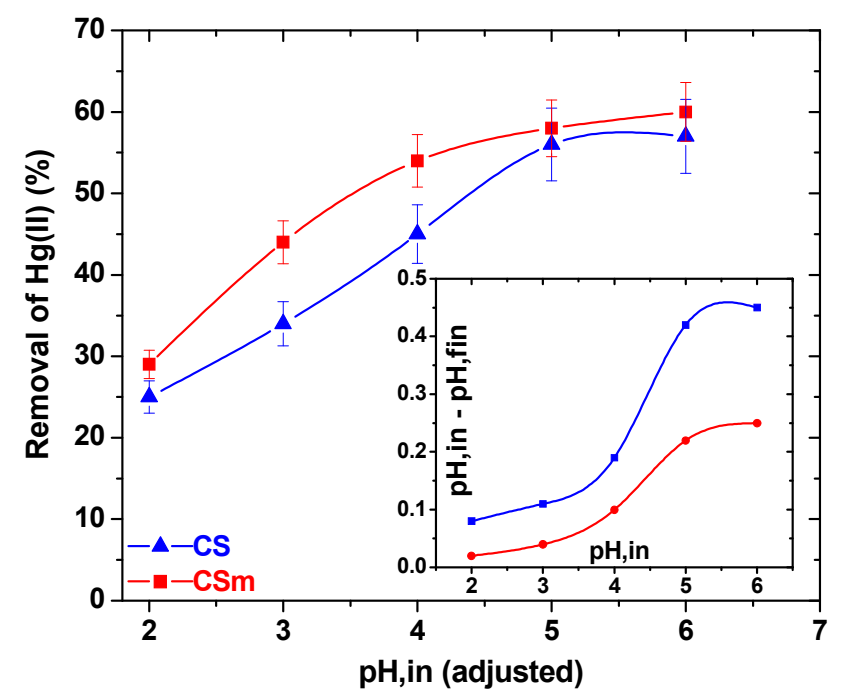

\subsubsection{Effect of Contact Time}

Figure 9a,b,c show the effect of contact time on adsorption. The fitting was performed using pseudo-first, -second order and Elovich equations. Table 2 presents the kinetic parameters resulted from the fitting. Figure 9a shows the plot of linearization of pseudo-first order model [45], where the slope $\left(-\mathrm{k}_{1} / 2.303\right)$ and intercept $\log \left(\mathrm{Q}_{\mathrm{e}}\right)$ of plot $\log \left(\mathrm{Q}_{\mathrm{e}}-\mathrm{Q}_{\mathrm{t}}\right)$ versus $\mathrm{t}$ was used to determine the pseudo-first order constant $\mathrm{k}_{1}$ and the equilibrium adsorption density $\mathrm{Q}_{\mathrm{e}, \mathrm{cal}}$. However, the experimental data deviated considerably from the theoretical data. The correlation coefficients $\left(\mathrm{R}^{2}\right)$ obtained were not as high as those for pseudo-second equation $\left(\mathrm{R}_{\mathrm{CS}}^{2}=0.964\right.$ and $\left.\mathrm{R}_{\mathrm{CSm}}^{2}=0.729\right)$. Also, the adsorption equilibrium values $\left(\mathrm{Q}_{\mathrm{e}, \mathrm{cal}}\right)$ found gave significant deviation for both adsorbents. In the case of CS, the difference was $14 \mathrm{mg} / \mathrm{g}\left(\mathrm{Q}_{\mathrm{e}, \mathrm{cal}}=42 \mathrm{mg} / \mathrm{g}\right.$ and $\left.\mathrm{Q}_{\mathrm{e}, \mathrm{exp}}=56 \mathrm{mg} / \mathrm{g}\right)$, while for CSm the deviation was very high, equal to $40 \mathrm{mg} / \mathrm{g}\left(\mathrm{Q}_{\mathrm{e}, \mathrm{cal}}=18 \mathrm{mg} / \mathrm{g}\right.$; $\left.\mathrm{Q}_{\mathrm{e}, \exp }=58 \mathrm{mg} / \mathrm{g}\right)$. These findings suggest that this adsorption system is not a pseudo-first order reaction. 
Figure 9. Effect of contact time on adsorption of $\mathrm{Hg}(\mathrm{II})$ onto $\mathrm{CS}$ and $\mathrm{CSm}$ : fitting to (a) pseudo-first order equation; (b) pseudo-second order equation; (c) Elovich equation.

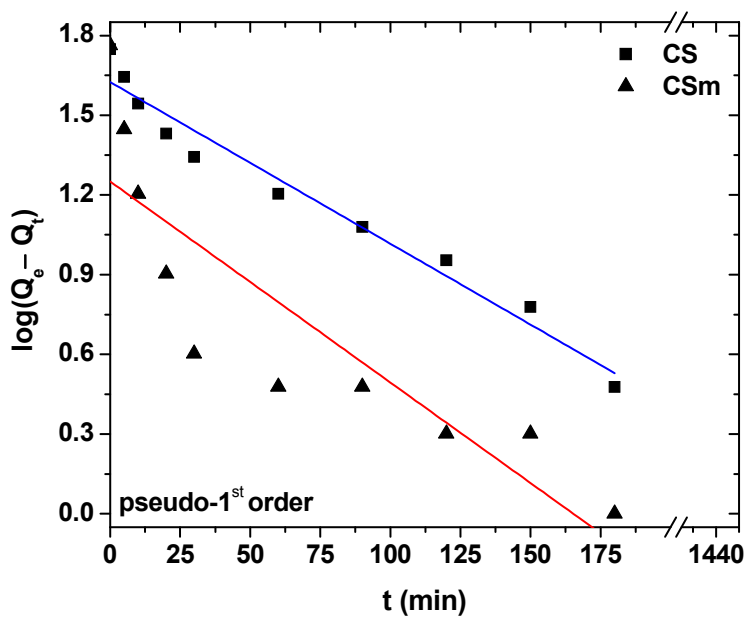

(a)

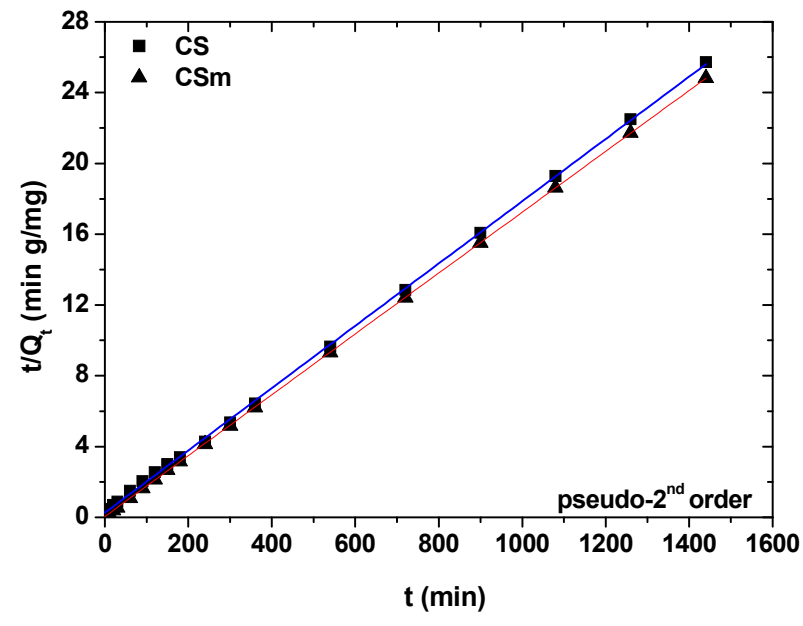

(b)

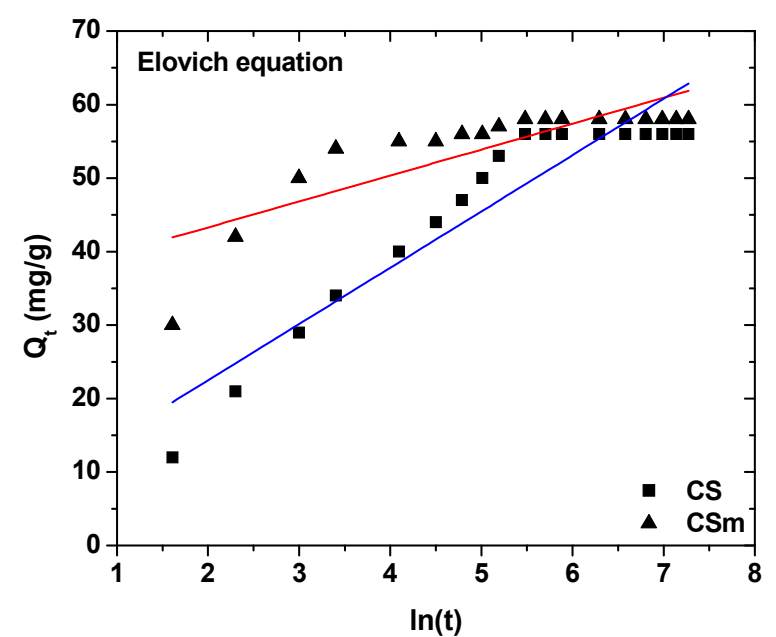

(c) 
Table 2. Kinetic constants for the adsorption of $\mathrm{Hg}(\mathrm{II})$ onto $\mathrm{CS}$ and $\mathrm{CSm}\left([\mathrm{Hg}(\mathrm{II})]_{0}=100 \mathrm{mg} / \mathrm{L}\right)$.

\begin{tabular}{ccccccccccc}
\hline & \multicolumn{4}{c}{ Pseudo-first order } & \multicolumn{2}{c}{ Pseudo-second order } & \multicolumn{3}{c}{ Elovich equation } \\
\hline & $\mathrm{Q}_{\mathrm{e}, \mathrm{exp}}$ & $\mathrm{k}_{1}$ & $\mathrm{Q}_{\mathrm{e}, \mathrm{cal}}$ & $\mathrm{R}^{2}$ & $\mathrm{k}_{2}$ & $\mathrm{Q}_{\mathrm{e}, \mathrm{cal}}$ & $\mathrm{R}^{2}$ & $\mathrm{a}$ & $\beta$ & $\mathrm{R}^{2}$ \\
\hline Adsorbent & $(\mathrm{mg} / \mathrm{g})$ & $\left(\mathrm{min}^{-1}\right)$ & $(\mathrm{mg} / \mathrm{g})$ & & $\left(\mathrm{g} \mathrm{mg}^{-1} \mathrm{~min}^{-1}\right)$ & $(\mathrm{mg} / \mathrm{g})$ & & $\left(\mathrm{mg} \mathrm{g}^{-1} \mathrm{~min}^{-1}\right)$ & $(\mathrm{g} / \mathrm{mg})$ & \\
$\mathrm{CS}$ & 56 & 0.0138 & 42 & 0.964 & $11.68 \times 10^{-4}$ & 56 & 0.999 & 39.33 & 0.0276 & 0.658 \\
$\mathrm{CSm}$ & 58 & 0.0174 & 18 & 0.729 & $57.65 \times 10^{-4}$ & 58 & 0.999 & 20.87 & 0.1395 & 0.884 \\
\hline
\end{tabular}

Furthermore, the experimental data fitted to the pseudo-second order equation (Figure 9b), calculating the respective parameters [46]. The slope $\left(1 / \mathrm{Q}_{\mathrm{e}}\right)$ and intercept $\left(1 / \mathrm{k}_{2} \mathrm{Q}_{\mathrm{e}}{ }^{2}\right)$ of plot $\left(\mathrm{t} / \mathrm{Q}_{\mathrm{t}}\right)$ versus $\mathrm{t}$ were used to calculate the parameters of $\mathrm{k}_{2}$ and $\mathrm{Q}_{\mathrm{e}, \mathrm{cal}}$. The straight lines in plots of Figure 9(b) showed an excellent agreement of experimental data with this model. The correlation coefficients for all adsorbents were equal to 0.999 . Also, the calculated $\mathrm{Q}_{\mathrm{e}, \mathrm{cal}}$ values are completely the same with those exported from the experimental data (CS: $\left.\mathrm{Q}_{\mathrm{e}, \mathrm{cal}}=\mathrm{Q}_{\mathrm{e}, \exp }=56 \mathrm{mg} / \mathrm{g} ; \mathrm{CSm}: \mathrm{Q}_{\mathrm{e}, \mathrm{cal}}=\mathrm{Q}_{\mathrm{e}, \exp }=58 \mathrm{mg} / \mathrm{g}\right)$. These findings indicate that the adsorption system studied belongs to the second-order kinetic model. A comment can be given for the adsorption rate, comparing the kinetics constants $\left(\mathrm{k}_{2}\right)$. According to Table 2, a relationship of $\mathrm{k}_{2, \mathrm{CSm}} / \mathrm{k}_{2, \mathrm{CS}}=4.67 \quad\left(\mathrm{k}_{2, \mathrm{CSm}}=57.65 \times 10^{-4} \mathrm{~g} \mathrm{mg}^{-1} \mathrm{~min}^{-1}\right.$ and $\mathrm{k}_{2, \mathrm{CS}}=11.68 \times 10^{-4} \mathrm{~g} \mathrm{mg}^{-1} \mathrm{~min}^{-1}$ ) can be easily extracted, revealing that magnetic chitosan adsorb/interact faster with $\mathrm{Hg}$ (II) ions than the non-magnetic derivative (CS). The latter can be attributed to the existence of $\mathrm{Fe}_{3} \mathrm{O}_{4}$ on $\mathrm{CSm}$ backbone, which may attract the ions.

Figure 9(c) shows a plot of linearization of Elovich model [47]. The slope and intercept of plots of $\mathrm{Q}_{\mathrm{t}}$ versus $\ln (\mathrm{t})$ were used to determine the constant $\beta_{\mathrm{el}}$ and the initial adsorption rate $\alpha$. However, the experimental data deviated considerably from the theoretical data. A comparison of the results with the correlation coefficients is shown in Table 2. The correlation coefficients for the Elovich kinetic model obtained at all the studies concentrations were low $\left(\mathrm{R}_{\mathrm{CS}}^{2}=0.658\right.$ and $\left.\mathrm{R}_{\mathrm{CSm}}^{2}=0.884\right)$. This suggests that this adsorption system is not an acceptable for this system.

\subsubsection{Isotherms-Thermodynamics}

The experimental data were fitted to the Langmuir [48], and Freundlich [49] isotherm model. Although the Langmuir and Freundlich isotherms were firstly introduced about 90 years ago, they still remain the two most commonly used adsorption isotherm equations. Their success undoubtedly reflects their ability to fit a wide variety of sorption data quite well. The Langmuir model represents chemisorption on a set of well defined localized adsorption sites, having the same adsorption energies independent of surface coverage and no interaction between adsorbed molecules. Langmuir isotherm assumes monolayer coverage of adsorbate onto adsorbent. Freundlich isotherm gives an expression encompassing the surface heterogeneity and the exponential distribution of active sites and their energies. This isotherm does not predict any saturation of the adsorbent surface; thus, infinite surface coverage is predicted, indicating physisorption on the surface.

Figure 10 presents the isotherms resulted from the adsorption of $\mathrm{Hg}$ (II) onto CS and CSm. Furthermore, Table 3 reports the maximum adsorption capacities $\left(\mathrm{Q}_{\max }\right)$ and the other isothermal parameters resulted from the fitting. The correlation coefficients $\left(\mathrm{R}^{2}>0.989\right)$, which is an indication of the successful fitting, confirm that the Langmuir model results in closer prediction of the isotherm to 
the experimental data. The calculated maximum adsorption capacities $\left(\mathrm{Q}_{\max }\right)$ for $\mathrm{Hg}$ (II) removal at $25^{\circ} \mathrm{C}(\mathrm{pH}=5)$ was 145 and $152 \mathrm{mg} / \mathrm{g}$ for $\mathrm{CS}$ and CSm, respectively. The latter confirms the similar adsorption behavior of two adsorbents.

Figure 10. Isotherms for the adsorption of $\mathrm{Hg}(\mathrm{II})$ onto $\mathrm{CS}$ and $\mathrm{CSm}$ at 25,45 and $65{ }^{\circ} \mathrm{C}$ (fitting to Langmuir and Freundlich equations).

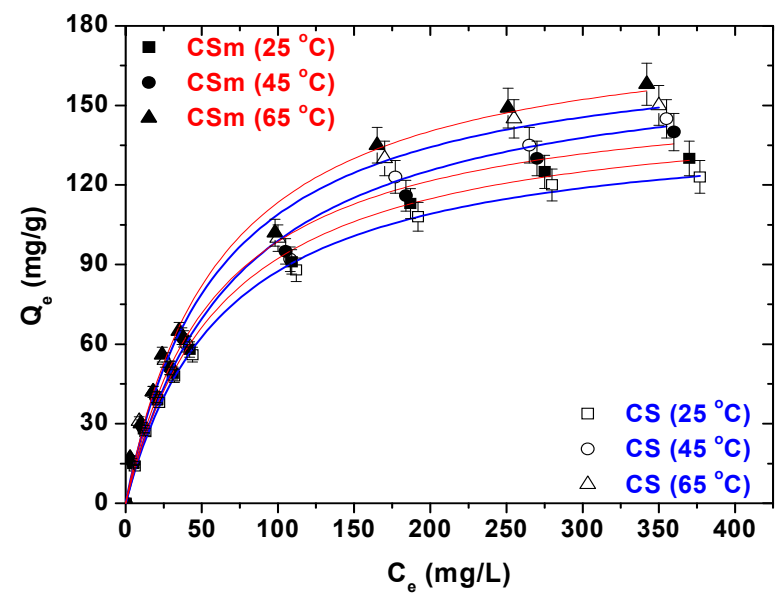

Table 3. Equilibrium parameters for the adsorption of $\mathrm{Hg}(\mathrm{II})$ onto $\mathrm{CS}$ and $\mathrm{CSm}$ at 25,45 and $65^{\circ} \mathrm{C}$.

\begin{tabular}{|c|c|c|c|c|c|c|c|}
\hline \multirow{2}{*}{ Adsorbent } & \multicolumn{4}{|c|}{ Langmuir equation } & \multicolumn{3}{|c|}{ Freundlich equation } \\
\hline & $\mathrm{T}\left({ }^{\circ} \mathrm{C}\right)$ & $Q_{\max }(\mathrm{mg} / \mathrm{g})$ & $K_{L}(\mathrm{~L} / \mathrm{mg})$ & $\mathbf{R}^{2}$ & $K_{F}\left(m g^{(n-1) / n} L^{1 / n} g^{-1}\right)$ & $\mathbf{n}$ & $\mathbf{R}^{2}$ \\
\hline \multirow[t]{3}{*}{ CS } & 25 & 145 & 0.015 & 0.998 & 10.95 & 2.37 & 0.977 \\
\hline & 45 & 171 & 0.014 & 0.992 & 10.93 & 2.22 & 0.976 \\
\hline & 65 & 175 & 0.017 & 0.989 & 13.86 & 2.89 & 0.976 \\
\hline \multirow[t]{3}{*}{$\mathrm{CSm}$} & 25 & 152 & 0.016 & 0.996 & 11.57 & 2.37 & 0.972 \\
\hline & 45 & 158 & 0.017 & 0.994 & 12.54 & 2.39 & 0.988 \\
\hline & 65 & 184 & 0.017 & 0.991 & 13.72 & 2.32 & 0.976 \\
\hline
\end{tabular}

The effect of temperature on equilibrium is also presented in Figure 10. Increasing the temperature from 25 to $65{ }^{\circ} \mathrm{C}$, an increase of the $\mathrm{Q}_{\max }$ is observed. In particular, CS augmented its $\mathrm{Q}_{\max }$ from $145 \mathrm{mg} / \mathrm{g}$ at $25{ }^{\circ} \mathrm{C}$ to $171 \mathrm{mg} / \mathrm{g}$ at $45{ }^{\circ} \mathrm{C}$ (increase of $18 \%$ ) and finally $175 \mathrm{mg} / \mathrm{g}$ at $65{ }^{\circ} \mathrm{C}$ (increase of $2 \%$ ). Similarly, the magnetic derivative (CSm) improved its $\mathrm{Q}_{\max }$ from $152 \mathrm{mg} / \mathrm{g}$ at $25^{\circ} \mathrm{C}$ to $158 \mathrm{mg} / \mathrm{g}$ at $45{ }^{\circ} \mathrm{C}$ (increase of $4 \%$ ) and finally $184 \mathrm{mg} / \mathrm{g}$ at $65{ }^{\circ} \mathrm{C}$ (increase of $16 \%$ ). However, an interesting finding of the above is the different-type change of $\mathrm{Q}_{\max }$ of two materials during the increase of temperature adsorption. Although, CS increased its $\mathrm{Q}_{\max } 18 \%$ from 25 to $45^{\circ} \mathrm{C}$, a nearly zero change was observed from 45 to $65^{\circ} \mathrm{C}(2 \%)$. In the case of CSm, the reverse fact was observed: CSm slightly increased its $\mathrm{Q}_{\max }$ from 25 to $45^{\circ} \mathrm{C}(4 \%)$, while a more intense increase was for the temperatures from 45 to $65^{\circ} \mathrm{C}(16 \%)$. The difference of the temperature-behavior of materials could be explained due to their difference modification and the existence of magnetism on CSm. The latter can behave in different manner for various temperatures. In general, as the majority of the chitosan-based materials [4], the $\mathrm{Q}_{\max }$ augmentation with temperature increase is caused by the enhancement of the number of adsorption sites; the latter is due to the weakening and/or breaking of many structural bonds of 
network, existed near the edge of the active surface sites of materials. Another, possible explanation is the increase of diffusion (mainly surface diffusion [50]), which helps the penetration of mercury ions inside the structural network of materials. Also, some works revealed the role of the formation of new active adsorption sites at high temperatures [51].

Based on the equilibrium data of isotherms, thermodynamic parameters were calculated. The Gibbs free energy change, $\Delta \mathrm{G}^{0}(\mathrm{~kJ} / \mathrm{mol})$, of the adsorption process is related to the equilibrium constant $\left(\mathrm{K}_{\mathrm{c}}\right)$ by the Van't Hoff equation (where $\mathrm{R}$ is the universal gas constant and is equal to $8.314 \mathrm{~J} / \mathrm{mol} \mathrm{K}$ ) [52]:

$$
\Delta \mathrm{G}^{0}=-\mathrm{R} \mathrm{T} \ln \left(\mathrm{K}_{\mathrm{c}}\right)
$$

The constant $\mathrm{K}_{\mathrm{c}}$ can be calculated as $\mathrm{K}_{\mathrm{c}}=\mathrm{C}_{\mathrm{s}} / \mathrm{C}_{\mathrm{e}}$ (where $\mathrm{C}_{\mathrm{s}}(\mathrm{mg} / \mathrm{L})$ is the amount adsorbed on solid at equilibrium). In addition, $\Delta \mathrm{G}^{0}$ is related to the change in entropy $\left(\Delta \mathrm{S}^{0}, \mathrm{~kJ} / \mathrm{mol} \mathrm{K}\right)$ and the heat of adsorption $\left(\Delta \mathrm{H}^{0}, \mathrm{~kJ} / \mathrm{mol}\right)$ at a constant temperature $\mathrm{T}(\mathrm{K})$, as follows:

$$
\Delta \mathrm{G}^{0}=\Delta \mathrm{H}^{0}-\mathrm{T} \Delta \mathrm{S}^{0}
$$

From Equations (2) and (3):

$$
\ln \left(\mathrm{K}_{\mathrm{c}}\right)=\left(\frac{-\Delta \mathrm{H}^{0}}{\mathrm{R}}\right) \frac{1}{\mathrm{~T}}+\frac{\Delta \mathrm{S}^{0}}{\mathrm{R}}
$$

The values of $\Delta \mathrm{H}^{0}$ and $\Delta \mathrm{S}^{0}$ were calculated from the slope and intercept of the plot between $\ln \left(\mathrm{K}_{\mathrm{c}}\right)$ versus $(1 / \mathrm{T})$.

The above thermodynamic parameters, at selected $\mathrm{Hg}$ (II) concentrations and all temperatures, are given in Table $4(\mathrm{pH}=5)$. The negative values of $\Delta \mathrm{G}^{0}$ showed the spontaneous adsorption of mercury ions on the adsorbent. Also, the increase found in the negative value of $\Delta \mathrm{G}^{0}$ with an increase in temperature implies that lower temperature makes the adsorption easier. The values of $\Delta \mathrm{H}^{0}$ were found to be positive, suggesting an endothermic process, where the adsorbate species (mercury ions) have to displace more than one water molecule for their adsorption, resulting in the endothermicity of the adsorption process. On the contrary, in a case of negative $\Delta \mathrm{H}^{0}$ values, it would be indicated the exothermic nature of the process, thereby demonstrating that the process would be stable energetically. In an exothermic process, the total energy absorbed in bond breaking would be less than the total energy released in bond making between adsorbate and adsorbent, resulting in the release of extra energy in the form of heat. The magnitude of $\Delta \mathrm{H}^{0}$ may also give an idea (but not sure) about the type of adsorption. The heat evolved during physical adsorption is of the same order of magnitude as the heats of condensation, i.e., $2.1-20.9 \mathrm{~kJ} / \mathrm{mol}$, while the heats of chemisorption generally falls into a range of $80-200 \mathrm{~kJ} / \mathrm{mol}$. Moreover, the values of $\Delta \mathrm{S}^{0}$ were found to be positive. A positive value of $\Delta S^{0}$ reflects the affinity of the adsorbent towards the adsorbate species. In addition, positive value of $\Delta \mathrm{S}^{0}$ suggests increased randomness at the solid/solution interface with some structural changes in the adsorbate and adsorbent. The adsorbed solvent molecules, which are displaced by the adsorbate species, gain more translational entropy than is lost by the adsorbate ions/molecules, thus allowing for the prevalence of randomness in the system. The positive $\Delta S^{0}$ value also corresponds to an increase in the degree of freedom of the adsorbed species. 
Table 4. Thermodynamic parameters for the adsorption of $\mathrm{Hg}(\mathrm{II})$ onto $\mathrm{CS}$ and CSm.

\begin{tabular}{|c|c|c|c|c|c|c|c|}
\hline Adsorbent & $\mathrm{C}_{0}(\mathrm{mg} / \mathrm{L})$ & $T(K)$ & $Q_{e}(\mathrm{mg} / \mathrm{g})$ & $\mathbf{K}_{\mathbf{c}}$ & $\Delta \mathrm{G}^{0}(\mathrm{~kJ} / \mathrm{mol})$ & $\Delta \mathbf{H}^{0}(\mathrm{~kJ} / \mathrm{mol})$ & $\Delta S^{0}(\mathrm{~kJ} / \mathrm{mol} \mathrm{K})$ \\
\hline \multirow[t]{9}{*}{ CS } & 20 & 298 & 14.02 & 2.33 & -2.10 & & \\
\hline & & 318 & 15.06 & 3.00 & -2.90 & +18.38 & +0.068 \\
\hline & & 338 & 16.980 & 5.67 & -4.87 & & \\
\hline & 100 & 298 & 56.02 & 1.27 & -0.60 & & \\
\hline & & 318 & 60.08 & 1.50 & -1.07 & +6.10 & +0.023 \\
\hline & & 338 & 62.99 & 1.70 & -1.50 & & \\
\hline & 500 & 298 & 123.10 & 0.33 & -0.11 & & \\
\hline & & 318 & 145.04 & 0.41 & -1.44 & +5.78 & +0.010 \\
\hline & & 338 & 150.03 & 0.43 & -2.44 & & \\
\hline \multirow[t]{9}{*}{$\mathrm{CSm}$} & 20 & 298 & 15.11 & 3.00 & -0.50 & & \\
\hline & & 318 & 16.02 & 4.00 & -0.80 & +13.27 & +0.054 \\
\hline & & 338 & 17.08 & 5.67 & -3.09 & & \\
\hline & 100 & 298 & 58.12 & 1.38 & -0.20 & & \\
\hline & & 318 & 61.99 & 1.63 & -0.85 & +6.21 & +0.024 \\
\hline & & 338 & 65.03 & 1.86 & -2.52 & & \\
\hline & 500 & 298 & 130.07 & 0.35 & -0.17 & & \\
\hline & & 318 & 139.89 & 0.39 & -2.03 & +5.70 & +0.010 \\
\hline & & 338 & 158.01 & 0.46 & -2.80 & & \\
\hline
\end{tabular}

\subsection{Desorption-Reuse}

Firstly, desorption $\mathrm{pH}-$-effect experiments were carried out in order to find the optimum $\mathrm{pH}$ desorption conditions. Figure 11 showed that the $\mathrm{pH}$-trend of curves were different of that of adsorption. The main adsorption interaction between the chitosan derivatives prepared and $\mathrm{Hg}$ (II) was the chelation between mercury ions and amino groups of chitosan. However, the chelation potential is not the same both at acidic and neutral (or alkaline) $\mathrm{pH}$ values, given the transformation to strongly protonated amino groups at acidic media, where the chelation did not favor [4]. So, increasing the $\mathrm{pH}$ values, the conditions become milder and the chelation mechanism becomes stronger, affecting consequently the $\mathrm{Hg}$ (II) removal. However, given the adsorption process is not considered to be fully reversible, incomplete desorption can be suspected for all $\mathrm{pH}$ values and especially at $\mathrm{pH}=2$ (where found to be the optimum). For desorption process, the maximum desorption percentages were found to be at acidic conditions. This could be explained by the fact that the chelated bonds between $\mathrm{Hg}(\mathrm{II})$ ions and amino groups of chitosan were weakened decreasing the $\mathrm{pH}$ of solution, so the desorption presented higher percentages at acidic $\mathrm{pH}$ values [4].

The inset of Figure 11 shows the reuse potential of the materials studied via sequential cycles of adsorption-desorption. The reduction in adsorption percentages from the 1 st to 4 th cycle was $26 \%$ for CS (from $56 \%$ to $30 \%$ ) and only $10 \%$ for CSm (from $58 \%$ to $48 \%$ ). The magnetic derivative presented more stable behavior during the cycles of reuse because of its more complex network. In general, the decrease of the adsorption efficiency occurred can be attributed to several reasons as: (i) a progressive saturation of the active sites/groups of the adsorbent by mercury(II) ions, (ii) a degradation of material due to extreme $\mathrm{pH}$ conditions, and (iii) a progressive blocking of the active sites of adsorbents by possible impurities caused a slight decrease in the adsorption potential. However, in magnetic chitosan 
derivatives, the reuse ability is very high since even after the $4^{\text {th }}$ cycle ( $10 \%$ reduction), suggesting that they are promising candidates for the practical use in wastewater treatment technologies.

Figure 11. Effect of $\mathrm{pH}$ on the desorption of $\mathrm{Hg}(\mathrm{II})$ from $\mathrm{CS}$ and $\mathrm{CSm}$ (inset: cycles of reuse).

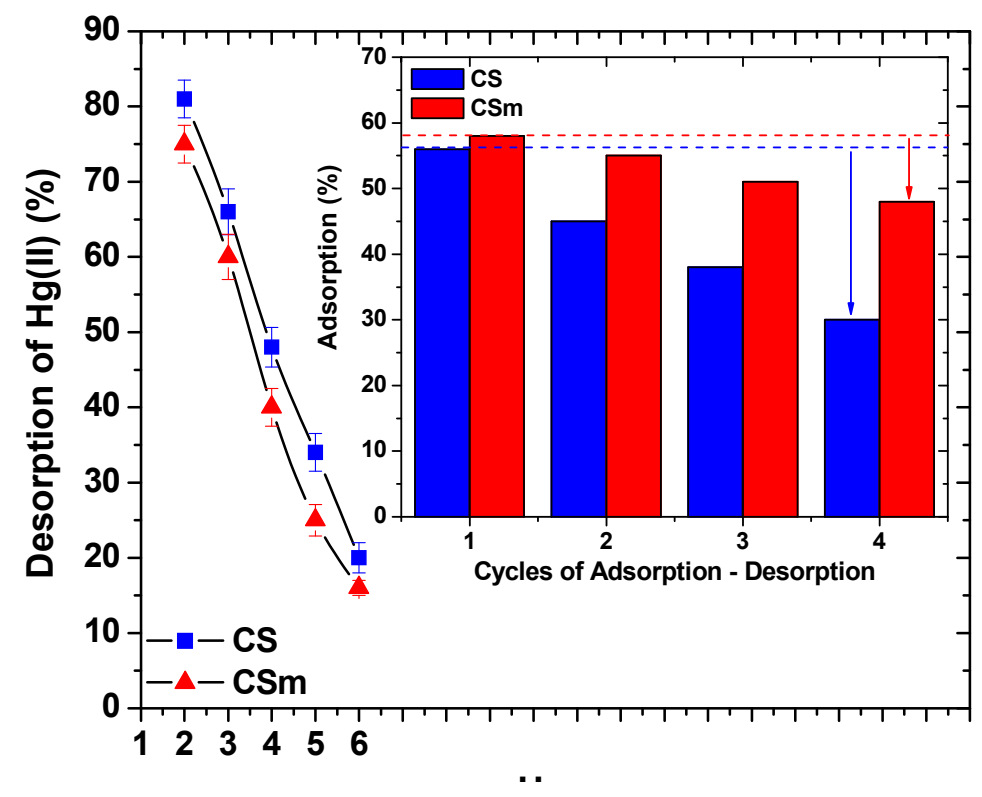

\section{Materials and Methods}

\subsection{Materials}

Commercial chitosan of high molecular weight was purified by extraction with acetone in a Soxhlet apparatus for $24 \mathrm{~h}$. Then, its drying was carried out under vacuum at $20{ }^{\circ} \mathrm{C}$, so the final purified chitosan product was obtained (denoted as CSp). Its average molecular weight was estimated at $3.55 \times 10^{5} \mathrm{~g} / \mathrm{mol}$ and the degree of deacetylation was $82 \mathrm{wt} \%$ [2]. The cross-linking agent used was glutaraldehyde (GLA, $50 \mathrm{wt} \%$ in water). Cross-linker was used, because chitosan presents high swelling degree in aqueous solutions [28]. In order to overcome this problem and given the use of chitosan (in this study) as adsorbent, it has to be cross-linked. $\mathrm{FeCl}_{2} \cdot 4 \mathrm{H}_{2} \mathrm{O}$ (puriss. pa. $>99.0 \%$ ) and $\mathrm{FeCl}_{3} \cdot 6 \mathrm{H}_{2} \mathrm{O}$ (puriss. pa. $>99.0 \%$ ) were used in the synthesis of magnetic nanoparticles. For the preparation of stock aqueous mercury(II) solutions, $\mathrm{Hg}\left(\mathrm{NO}_{3}\right)_{2} \cdot \mathrm{H}_{2} \mathrm{O}$ was used (puriss. pa. $\geq 98.5 \%$ ). All reagents were purchased from Sigma-Aldrich (Munich, Germany), while all solvents used were of analytical grade.

\subsection{Synthesis of Adsorbents}

The synthesis of chitosan derivatives was in accordance with previously published works of our research team [20,29]. The particle size of the adsorbents prepared was in the range of $75-125 \mu \mathrm{m}$ (after grounding and sieving). 


\subsubsection{Synthesis of Cross-linked Chitosan (CS)}

$2 \mathrm{~g}$ of CSp was dissolved in $400 \mathrm{~mL}$ of acetic solution $(2 \% \mathrm{v} / \mathrm{v})$. Then, $15 \mathrm{~mL}$ of GLA [approximately 2:1 aldehyde groups $(-\mathrm{CHO})$ of GLA per initial amino group $\left(-\mathrm{NH}_{2}\right)$ of chitosan] were added into the reaction flask to mix with the solution and was vigorously stirred at $25^{\circ} \mathrm{C}$ for $3 \mathrm{~h}$. The precipitate was washed with ethanol and distilled water in turn and dried in a vacuum oven at $45{ }^{\circ} \mathrm{C}$. The obtained product was the cross-linked derivative of chitosan (CS).

\subsubsection{Synthesis of Magnetic Cross-linked Chitosan (CSm)}

Initially, the preparation of magnetic nanoparticles was carried out mixing $\mathrm{FeCl}_{2} \cdot 4 \mathrm{H}_{2} \mathrm{O}(3.5 \mathrm{~g})$, $\mathrm{FeCl}_{3} \cdot 6 \mathrm{H}_{2} \mathrm{O}(9.5 \mathrm{~g})$ and double distilled water $(400 \mathrm{~mL})$ and stirring in a water bath at $60{ }^{\circ} \mathrm{C}$ under nitrogen for $1 \mathrm{~h}$. Ammonia solution was added dropwise, purged with nitrogen, until $\mathrm{pH}=10$. The precipitate obtained was decanted in a dialysis tubing cellulose membrane (Sigma Co.) and the latter was placed in a bath filled with distilled water. The chloride ions presented in the initial suspension were slowly removed by osmosis through the membrane. The existence of $\mathrm{Cl}^{-}$ions in the water bath was tested with a solution of $\mathrm{AgNO}_{3}(0.1 \mathrm{M})$. The water of the bath was replaced several times, until no more chloride ions were detectable in it. The resulting cake on the membrane surface after decanting was freeze-dried in a bench freeze drier (Christ Alpha 1-4, Osterode am Harz, Germany).

CSp (2 g) was dissolved in acetic acid solution $(400 \mathrm{~mL}, 2 \% \mathrm{v} / \mathrm{v})$. The prepared magnetic nanoparticles $(0.75 \mathrm{~g})$ were added to the above chitosan solution and the mixture was sonicated for 30 min. Then, GLA was added to mixture solution in order to cross-link chitosan. Thus, GLA (15 mL) [like for CS, the ratio was 2:1 aldehyde groups $(-\mathrm{CHO})$ of GLA per initial amino group $\left(-\mathrm{NH}_{2}\right)$ of chitosan] were added into reaction flask to mix with the solution and was vigorously stirred at $60{ }^{\circ} \mathrm{C}$ for $2 \mathrm{~h}$. The precipitate was washed with ethanol and distilled water in turn and dried in a vacuum oven at $50{ }^{\circ} \mathrm{C}$. The obtained product was the magnetic cross-linked chitosan derivative (CSm).

\subsection{Experimental Procedure}

\subsubsection{Adsorption-Desorption experiments}

The effect of $\mathrm{pH}$ on adsorption was conducted by mixing adsorbent $(0.02 \mathrm{~g})$ with metal aqueous solution $\left(20 \mathrm{~mL}, \mathrm{C}_{0, \mathrm{Hg}(\mathrm{II})}=100 \mathrm{mg} / \mathrm{L}\right)$. The adjustment of $\mathrm{pH}$ can be characterized as very critical, given the variable nature of this parameter. For this reason, the adjustment of $\mathrm{pH}$ was done with microadditions of $\mathrm{HNO}_{3}$ or $\mathrm{NaOH}$. The concentrations of acid and base used were low $(0.01 \mathrm{M})$ in order to have even more accuracy of $\mathrm{pH}$ adjustment $( \pm 0.03)$ not only at extremely acidic conditions $(\mathrm{pH}=2)$ but also at low-acidic ones $(\mathrm{pH}=5)$. The suspension was shaken for $24 \mathrm{~h}(\mathrm{~N}=160 \mathrm{rpm})$ into a water bath to control the temperature at $25^{\circ} \mathrm{C}$ (Julabo SW-21C, Seelbach, Germany). The optimum $\mathrm{pH}$ selected was 5.

Kinetic experiments were performed by mixing adsorbent $(0.02 \mathrm{~g})$ with aqueous metal solution $\left(20 \mathrm{~mL}, \mathrm{C}_{0, \mathrm{Hg}(\mathrm{II})}=100 \mathrm{mg} / \mathrm{L}\right)$. The suspensions were shaken for $24 \mathrm{~h}$ at $\mathrm{pH}=5$ in water bath at $25{ }^{\circ} \mathrm{C}$ $(\mathrm{N}=160 \mathrm{rpm}$ ). Samples were collected at fixed-time intervals (from $5 \mathrm{~min}$ to $24 \mathrm{~h}$ ). Pseudo-first 
(Equation (5)) [45], pseudo-second order (Equation (6)) [46] and Elovich (Equation (7)) [47] equations were used to fit the kinetic experimental data:

$$
\begin{gathered}
\log \left(\mathrm{Q}_{\mathrm{e}}-\mathrm{Q}_{\mathrm{t}}\right)=\log \left(\mathrm{Q}_{\mathrm{e}}\right)-\left(\frac{\mathrm{k}_{1}}{2.303}\right) \mathrm{t} \\
\frac{\mathrm{t}}{\mathrm{Q}_{\mathrm{t}}}=\frac{1}{\mathrm{k}_{2} \mathrm{Q}_{\mathrm{e}}^{2}}+\left(\frac{1}{\mathrm{Q}_{\mathrm{e}}}\right) \mathrm{t} \\
\mathrm{Q}_{\mathrm{t}}=\frac{1}{\beta_{\mathrm{el}}} \ln \left(\mathrm{a} \cdot \beta_{\mathrm{el}}\right)+\frac{1}{\beta_{\mathrm{el}}} \ln (\mathrm{t})
\end{gathered}
$$

where $\mathrm{k}_{1}\left(\mathrm{~min}^{-1}\right)$ and $\mathrm{k}_{2}\left(\mathrm{~g} \mathrm{mg}^{-1} \min ^{-1}\right)$ are the rate constants for the pseudo-first and -second order kinetic equations, respectively; a $\left(\mathrm{mg} \mathrm{g}^{-1} \mathrm{~min}^{-1}\right)$ is the initial adsorption rate and $\beta_{\mathrm{el}}(\mathrm{g} / \mathrm{mg})$ is the desorption constant during any experiment exported from the Elovich equation.

The effect of temperature on adsorption was determined by mixing adsorbent $(0.02 \mathrm{~g})$ with of aqueous metal solutions of different initial concentrations $\left(20 \mathrm{~mL}, \mathrm{C}_{0, \mathrm{Hg}(\mathrm{II})}=0-500 \mathrm{mg} / \mathrm{L}\right)$. The suspensions were shaken for $24 \mathrm{~h}$ at $\mathrm{pH}=5$ in water bath at $25,45,65{ }^{\circ} \mathrm{C}(\mathrm{N}=160 \mathrm{rpm})$. The resulted equilibrium data were fitted to the Langmuir model [Equation (8)] [48] and the Freundlich equation (Equation (9)) [49]:

$$
\begin{gathered}
Q_{e}=\frac{Q_{\max } K_{L} C_{e}}{1+K_{L} C_{e}} \\
Q_{e}=K_{F}\left(C_{e}\right)^{1 / n}
\end{gathered}
$$

where $Q_{e}(\mathrm{mg} / \mathrm{g})$ is the equilibrium metal concentration in the solid phase; $\mathrm{Q}_{\max }(\mathrm{mg} / \mathrm{g})$ is the maximum amount of adsorption; $\mathrm{K}_{\mathrm{L}}(\mathrm{L} / \mathrm{mg})$ is the Langmuir adsorption equilibrium constant; $\mathrm{K}_{\mathrm{F}}\left(\mathrm{mg}^{1-1 / \mathrm{n}} \mathrm{L}^{1 / \mathrm{n} / \mathrm{g}}\right)$ is the Freundlich constant representing the adsorption capacity; $\mathrm{n}$ (dimensionless) is the constant depicting the adsorption intensity.

The amount of total metal uptake at equilibrium $\mathrm{Q}_{\mathrm{e}}(\mathrm{mg} / \mathrm{g})$ was calculated using the mass balance equation:

$$
\mathrm{Q}_{\mathrm{e}}=\frac{\left(\mathrm{C}_{0}-\mathrm{C}_{\mathrm{e}}\right) \mathrm{V}}{\mathrm{m}}
$$

where $\mathrm{m}(\mathrm{g})$ is the mass of adsorbent; $\mathrm{V}(\mathrm{L})$ the volume of adsorbate; $\mathrm{C}_{0}$ and $\mathrm{C}_{\mathrm{e}}(\mathrm{mg} / \mathrm{L})$ are the initial and equilibrium metal concentrations in the liquid phase, respectively.

The desorption of $\mathrm{Hg}$ (II) from synthesized chitosan adsorbents was also investigated. Before desorption, adsorbents have to be loaded in an adsorption step. In this stage (adsorption), adsorbent $(0.02 \mathrm{~g})$ was added in conical flasks with $100 \mathrm{mg} / \mathrm{L} \mathrm{Hg}$ (II) $(20 \mathrm{~mL})$ at $\mathrm{pH}=5$. The agitation rate was $160 \mathrm{rpm}$ and the contact time was $24 \mathrm{~h}$ at $25^{\circ} \mathrm{C}$. Afterwards, the samples were collected and filtered, using fixed pore-sized membranes. A small fraction of $\mathrm{Hg}(\mathrm{II})(1 \%-2 \%)$ and adsorbent $(1 \%)$ were retained on the filter membrane; these small variations due to filtration were neglected. Desorption experiments were carried out by mixing the collected, after adsorption, amount of $\mathrm{Hg}$ (II)-loaded chitosan adsorbents $(0.02 \mathrm{~g})$ with metal aqueous solutions of $20 \mathrm{~mL}$ (same volume as in the adsorption step) over a $\mathrm{pH}$ range between 2 and 6 , at $25^{\circ} \mathrm{C}$ for $24 \mathrm{~h}(\mathrm{~N}=160 \mathrm{rpm})$. The quantitative evaluation of 
desorption was realized using desorption percentages, calculated from the difference between the loaded amount of $\mathrm{Hg}$ (II) on adsorbent after adsorption and the amount of $\mathrm{Hg}$ (II) in solution after desorption. This experimental procedure was done to determine the optimum desorption $\mathrm{pH}$ value of the $\mathrm{Hg}(\mathrm{II})$-loaded adsorbents.

After the end of each adsorption or desorption experiment series, the measurement and analysis of $\mathrm{Hg}$ (II) residual concentration in the liquid phase was realized. In particular, samples were collected from the supernatant and filtered in fixed pore-sized membranes $(0.40 \mu \mathrm{m})$ purchased from Schleicher \& Schuell-MicroScience (Florida, FL, USA). Hg(II) was measured using flame atomic absorption spectrophotometer (Perkin-Elmer $1100 \mathrm{~B}$, Dresden, Germany) at $254 \mathrm{~nm}$. The detection limit of FAAS was $300 \mu \mathrm{g} / \mathrm{L}$, that is much lower to the $\mathrm{Hg}$ (II) residual concentrations of this study. The detection limits are based on 98\% confidence level (three standard deviations). The absorbance was converted to concentration using calibration curve.

\subsubsection{Instrumentation-Characterization}

Scanning electron microscopy (SEM) images were performed on a Zeiss Supra 55 VP instrument (Jena, Germany). The accelerating voltage was $15.00 \mathrm{kV}$ and the scanning was performed in situ on a sample powder. EDAX analysis was done at magnification $10 \mathrm{~K}$ and led to the maps of elements and elemental analysis. The FTIR spectra of the samples were taken with a FTIR-2000 spectrometer (Perkin Elmer, Dresden, Germany) using $\mathrm{KBr}$ disks prepared by mixing $0.5 \%$ of finely ground sample in $\mathrm{KBr}$. Pellet made of pure $\mathrm{KBr}$ was used as the reference sample for background measurements. The spectra were recorded from 4,000 to $400 \mathrm{~cm}^{-1}$ at a resolution of $4 \mathrm{~cm}^{-1}$ with 64 co-added scans. The spectra presented are baseline corrected and converted to the transmittance mode. Thermal analysis was carried out using a TA Instrument thermal analyzer (SDT) Q500 model (TA Instruments, New York, NY, USA). The instrument had the following settings: (i) heating rate of $10 \mathrm{~K} / \mathrm{min}$ and (ii) flow rate of nitrogen atmosphere equal to $100 \mathrm{~mL} / \mathrm{min}$. Approximately $25 \mathrm{mg}$ of sample was used for each measurement. X-ray powder diffraction (XRD) patterns were recorded on a PW1820 diffractometer model (Philips, New York, NY, USA) with a CuK $\alpha$ radiation for crystalline phase identification. The sample was scanned from $20^{\circ}$ to $80^{\circ}$. The magnetic property was measured on a vibrating sample magnetometer (VSM) (Oxford Instruments, Oxford, UK) at room temperature.

Swelling experiments were performed at $\mathrm{pH}=5$, because at this $\mathrm{pH}$ values the adsorption was found to be optimum. In particular, $1 \mathrm{~g}$ of adsorbent was immersed in deionized water and left to be swollen for $24 \mathrm{~h}$. The $\mathrm{pH}$ adjustment was achieved with $0.01 \mathrm{M} \mathrm{HNO}_{3}$ and/or $0.01 \mathrm{M} \mathrm{NaOH}$. After the $\mathrm{pH}$ adjustment, the material was allowed to be completely swollen, until there was no further weight increase. The swollen samples were weighted and the swelling percentage (SP, \%) was calculated as:

$$
\mathrm{SP}=\left(\frac{\mathrm{W}_{\mathrm{t}}-\mathrm{W}_{0}}{\mathrm{~W}_{0}}\right) \cdot 100 \%
$$

where $\mathrm{W}_{\mathrm{t}}(\mathrm{g})$ is the weight of the swollen sample at time $\mathrm{t}$, and $\mathrm{W}_{0}(\mathrm{~g})$ is the initial weight of the sample before swelling. 


\section{Conclusions}

The current work compares adsorptively two differently modified derivatives: (i) cross-linked with glutaraldehyde (CS), and (ii) cross-linked with glutaraldehyde and functionalized with magnetic nanoparticles $(\mathrm{CSm})$. The main adsorption mechanism between amino groups of chitosan and mercury(II) ions were explained via characterization with various techniques. SEM/EDAX, FTIR, XRD, DTG, DTA, VSM, swelling tests). The optimum $\mathrm{pH}$ for adsorption was 5 and for desorption it was 2. CSm presented faster adsorption than CS, while its $\mathrm{Q}_{\max }$ at $25^{\circ} \mathrm{C}$ was $152 \mathrm{mg} / \mathrm{g}(145 \mathrm{mg} / \mathrm{g}$ for $\mathrm{CSm}$ ). Increasing the temperature, an increase of $\mathrm{Q}_{\max }$ was observed for both derivatives. According to thermodynamic analysis, $\Delta H^{0}>0$ suggested the endothermic nature of the process, $\Delta G^{0}<0$ suggested the spontaneity of the process, and $\Delta S^{0}>0$ showed the increased randomness at the solid/liquid interface. The reuse ability of the adsorbents prepared was confirmed with sequential cycles of adsorption-desorption. The reuse ability of CSm is very high since even after the $4^{\text {th }}$ cycle the reduction of the adsorption ability was $10 \%$ (26\% for CS).

\section{Acknowledgments}

This research has been co-financed by the European Union (European Social Fund - ESF) and Greek national funds through the Operational Program "Education and Lifelong Learning" of the National Strategic Reference Framework (NSRF)-Research Funding Program: THALES. Investing in Knowledge Society through the European Social Fund.

\section{Conflict of Interest}

The authors declare no conflict of interest.

\section{References}

1. Muzzarelli, R.A.A.; Muzzarelli, C. Chitosan chemistry: Relevance to the biomedical sciences. Adv. Polym. Sci. 2005, 186, 151-209.

2. Rinaudo, M. Chitin and chitosan: Properties and applications. Prog. Polym. Sci. 2006, 31, 603-632.

3. Zhang, Z.; Cui, H. Biodegradability and Biocompatibility Study of Poly(Chitosan-g-lactic Acid) Scaffolds. Molecules 2012, 17, 3243-3258.

4. Guibal, E. Interactions of metal ions with chitosan-based sorbents: A review. Sep. Purif. Technol. 2004, 38, 43-74.

5. Radwan, A.A.; Alanazi, F.K.; Alsarra, I.A. Microwave irradiation-assisted synthesis of a novel crown ether crosslinked chitosan as a chelating agent for heavy metal ions $\left(\mathrm{M}^{+\mathrm{n}}\right)$. Molecules $\mathbf{2 0 1 0}$, $15,6257-6268$.

6. Chassary, P.; Vincent, T.; Guibal, E. Metal anion sorption on chitosan and derivative materials: A strategy for polymer modification and optimum use. React. Funct. Polym. 2004, 60, 137-149.

7. Batista, A.C.L.; Villanueva, E.R.; Amorim, R.V.S.; Tavares, M.T.; Campos-Takaki, G.M. Chromium (VI) Ion Adsorption Features of Chitosan Film and Its Chitosan/Zeolite Conjugate 13X Film. Molecules 2011, 16, 3569-3579. 
8. Kim, G.; Kim, N.; Kim, D.; Kwon, J.; Min, B.-H. An electrostatically crosslinked chitosan hydrogel as a drug carrier. Molecules 2012, 17, 13704-13711.

9. Varma, A.J.; Deshpande, S.V.; Kennedy, J.F. Metal complexation by chitosan and its derivatives: A review. Carbohyd. Polym. 2004, 55, 77-93.

10. Dai, J.; Ren, F.L.; Tao, C.Y. Adsorption behavior of $\mathrm{Fe}(\mathrm{II})$ and $\mathrm{Fe}(\mathrm{III})$ ions on thiourea cross-linked chitosan with Fe(III) as template. Molecules 2012, 17, 4388-4399.

11. Yeganeh, M.; Afyuni, M.; Khoshgoftarmanesh, A.H.; Khodakarami, L.; Amini, M.; Soffyanian, A.R.; Schulin, R. Mapping of human health risks arising from soil nickel and mercury contamination. J. Hazard. Mater. 2013, 244-245, 225-239.

12. Rocha, C.G.; Zaia, D.A.M.; Alfaya, R.V.d.S.; Alfaya, A.A.d.S. Use of rice straw as biosorbent for removal of $\mathrm{Cu}(\mathrm{II}), \mathrm{Zn}(\mathrm{II}), \mathrm{Cd}(\mathrm{II})$ and $\mathrm{Hg}(\mathrm{II})$ ions in industrial effluents. J. Hazard. Mater. 2009, $166,383-388$.

13. Jeon, C.; Höll, W.H. Chemical modification of chitosan and equilibrium study for mercury ion removal. Water Res. 2003, 37, 4770-4780.

14. Jeon, C.; Park, K.H. Adsorption and desorption characteristics of mercury(II) ions using aminated chitosan bead. Water Res. 2005, 39, 3938-3944.

15. Vieira, R.S.; Oliveira, M.L.M.; Guibal, E.; Rodríguez-Castellón, E.; Beppu, M.M. Copper, mercury and chromium adsorption on natural and crosslinked chitosan films: An XPS investigation of mechanism. Colloid. Surface. A 2011, 374, 108-114.

16. Vieira, R.S.; Beppu, M.M. Interaction of natural and crosslinked chitosan membranes with $\mathrm{Hg}(\mathrm{II})$ ions. Colloid. Surface. A 2006, 279, 196-207.

17. Kyzas, G.Z.; Kostoglou, M.; Lazaridis, N.K. Relating interactions of dye molecules with chitosan to adsorption kinetic data. Langmuir 2010, 26, 9617-9626.

18. Kyzas, G.Z.; Kostoglou, M.; Lazaridis, N.K.; Bikiaris, D.N. N-(2-Carboxybenzyl) grafted chitosan as adsorptive agent for simultaneous removal of positively and negatively charged toxic metal ions. J. Hazard. Mater. 2013, 244-245, 29-38.

19. Kyzas, G.Z.; Kostoglou, M.; Vassiliou, A.A.; Lazaridis, N.K. Treatment of real effluents from dyeing reactor: Experimental and modeling approach by adsorption onto chitosan. Chem. Eng. J. 2011, 168, 577-585.

20. Lazaridis, N.K.; Kyzas, G.Z.; Vassiliou, A.A.; Bikiaris, D.N. Chitosan derivatives as biosorbents for basic dyes. Langmuir 2007, 23, 7634-7643.

21. Lv, H.-X.; Zhang, Z.-H.; Wang, X.-P.; Cheng, Q.-Q.; Wang, W.; Huang, X.-H.; Zhou, J.-P.; Zhang, Q.; Hou, L.-L.; Huo, W. A biomimetic chitosan derivates: Preparation, characterization and transdermal enhancement studies of N-arginine chitosan. Molecules 2011, 16, 6778-6790.

22. Li, T.-T.; Liu, Y.-G.; Peng, Q.-Q.; Hu, X.-J.; Liao, T.; Wang, H.; Lu, M. Removal of lead(II) from aqueous solution with ethylenediamine-modified yeast biomass coated with magnetic chitosan microparticles: Kinetic and equilibrium modeling. Chem. Eng. J. 2013, 214, 189-197.

23. Yan, H.; Yang, L.; Yang, Z.; Yang, H.; Li, A.; Cheng, R. Preparation of chitosan/poly(acrylic acid) magnetic composite microspheres and applications in the removal of copper(II) ions from aqueous solutions. J. Hazard. Mater. 2012, 229-230, 371-380.

24. Elwakeel, K.Z. Removal of Cr(VI) from alkaline aqueous solutions using chemically modified magnetic chitosan resins. Desalination 2010, 250, 105-112. 
25. Liu, X.; Hu, Q.; Fang, Z.; Zhang, X.; Zhang, B. Magnetic chitosan nanocomposites: A useful recyclable tool for heavy metal ion removal. Langmuir 2009, 25, 3-8.

26. Donia, A.M.; Atia, A.A.; Elwakeel, K.Z. Selective separation of mercury(II) using magnetic chitosan resin modified with Schiff's base derived from thiourea and glutaraldehyde. J. Hazard. Mater. 2008, 151, 372-379.

27. Zhou, L.; Liu, Z.; Liu, J.; Huang, Q. Adsorption of $\mathrm{Hg}(\mathrm{II})$ from aqueous solution by ethylenediamine-modified magnetic crosslinking chitosan microspheres. Desalination 2010, 258, 41-47.

28. Berger, J.; Reist, M.; Mayer, J.M.; Felt, O.; Peppas, N.A.; Gurny, R. Structure and interactions in covalently and ionically crosslinked chitosan hydrogels for biomedical applications. Eur. J. Pharm. Biopharm. 2004, 57, 19-34.

29. Travlou, N.A.; Kyzas, G.Z.; Lazaridis, N.K.; Deliyanni, E.A. Functionalization of graphite oxide with magnetic chitosan for the preparation of a nanocomposite dye adsorbent. Langmuir 2013, 29 , $1657-1668$.

30. Seung, H.H. Thermal Reduction of Graphene Oxide. In Physics and Applications of GrapheneExperiments; Mikhailov, S., Ed. InTech: Rijeka, Croatia, 2011; pp. 73-90. Availbale online: http://www.intechopen.com (accesed on 19 April 2011).

31. Li, Y.; Chu, J.; Qi, J.; Li, X. An easy and novel approach for the decoration of graphene oxide by $\mathrm{Fe}_{3} \mathrm{O}_{4}$ nanoparticles. Appl. Surf. Sci. 2011, 257, 6059-6062.

32. Guo, J.; Chen, S.; Liu, L.; Li, B.; Yang, P.; Zhang, L.; Feng, Y. Adsorption of dye from wastewater using chitosan-CTAB modified bentonites. J. Colloid Interface Sci. 2012, 382, 61-66.

33. Krishna Rao, K.S.V.; Chung, I.; Ha, C.-S. Synthesis and characterization of poly(acrylamidoglycolic acid) grafted onto chitosan and its polyelectrolyte complexes ith hydroxyapatite. React. Funct. Polym. 2008, 68, 943-953.

34. Kuo, C.-H.; Liu, Y.-C.; Chang, C.-M.J.; Chen, J.-H.; Chang, C.; Shieh, C.-J. Optimum conditions for lipase immobilization on chitosan-coated Fe3O4 nanoparticles. Carbohyd. Polym. 2012, 87, 2538-2545.

35. Li, G.-Y.; Jiang, Y.-R.; Huang, K.-L.; Ding, P.; Chen, J. Preparation and properties of magnetic $\mathrm{Fe}_{3} \mathrm{O}_{4}$-chitosan nanoparticles. J. Alloy. Compd. 2008, 466, 451-456.

36. Ma, F.; Qu, R.; Sun, C.; Wang, C.; Ji, C.; Zhang, Y.; Yin, P. Adsorption behaviors of Hg(II) on chitosan functionalized by amino-terminated hyperbranched polyamidoamine polymers. J. Hazard. Mater. 2009, 172, 792-801.

37. Wang, Z.; Yin, P.; Qu, R.; Chen, H.; Wang, C.; Ren, S. Adsorption kinetics, thermodynamics and isotherm of $\mathrm{Hg}(\mathrm{II})$ from aqueous solutions using buckwheat hulls from Jiaodong of China. Food Chem. 2013, 136, 1508-1514.

38. Li, Q.; Sun, L.; Zhang, Y.; Qian, Y.; Zhai, J. Characteristics of equilibrium, kinetics studies for adsorption of $\mathrm{Hg}(\mathrm{II})$ and $\mathrm{Cr}(\mathrm{VI})$ by polyaniline/humic acid composite. Desalination 2011, 266, $188-194$.

39. Koong, L.F.; Lam, K.F.; Barford, J.; McKay, G. A comparative study on selective adsorption of metal ions using aminated adsorbents. J. Colloid Interface Sci. 2013, 395, 230-240. 
40. Zhou, Y.T.; Nie, H.L.; Branford-White, C.; He, Z.Y.; Zhu, L.M. Removal of $\mathrm{Cu}^{2+}$ from aqueous solution by chitosan-coated magnetic nanoparticles modified with $\alpha$-ketoglutaric acid. J. Colloid Interface Sci. 2009, 330, 29-37.

41. Vieira, R.S.; Beppu, M.M. Dynamic and static adsorption and desorption of $\mathrm{Hg}(\mathrm{II})$ ions on chitosan membranes and spheres. Water Res. 2006, 40, 1726-1734.

42. Fan, L.; Luo, C.; Lv, Z.; Lu, F.; Qiu, H. Preparation of magnetic modified chitosan and adsorption of $\mathrm{Zn}^{2+}$ from aqueous solutions. Colloid. Surface. B. 2011, 88, 574-581.

43. Jin, L.; Bai, R. Mechanisms of lead adsorption on chitosan/PVA hydrogel beads. Langmuir 2002, 18, 9765-9770.

44. Yuwei, C.; Jianlong, W. Preparation and characterization of magnetic chitosan nanoparticles and its application for $\mathrm{Cu}$ (II) removal. Chem. Eng. J. 2011, 168, 286-292.

45. Lagergren, S. About the theory of so-called adsorption of soluble substances. Handlingar 1898, $24,1-39$.

46. Ho, Y.S.; Ng, J.C.Y.; McKay, G. Kinetics of pollutant sorption by biosorbents: Review. Sep. Purif. Method. 2000, 29, 189-232.

47. Chien, S.H.; Clayton, W.R. Application of Elovich equation to the kinetics of phosphate release and sorption in soils. Soil Sci. Soc. Am. J. 1980, 44, 265-268.

48. Langmuir, I. The adsorption of gases on plane surfaces of glass, mica and platinum. J. Am. Chem. Soc. 1918, 40, 1361-1403.

49. Freundlich, H. Over the adsorption in solution. Z. Phys. Chem. 1906, 57, 385-470.

50. Kyzas, G.Z.; Kostoglou, M.; Lazaridis, N.K. Copper and chromium(VI) removal by chitosan derivatives-Equilibrium and kinetic studies. Chem. Eng. J. 2009, 152, 440-448.

51. Crini, G. Non-conventional low-cost adsorbents for dye removal: A review. Bioresource Technol. 2006, 97, 1061-1085.

52. Smith, J.M.; Van Ness, H.C. Introduction to Chemical Engineering Thermodynamics, 4th ed.; McGraw-Hill: New York, NY, USA, 1987.

Sample Availability: Samples of the adosrbents are available from the authors.

(C) 2013 by the authors; licensee MDPI, Basel, Switzerland. This article is an open access article distributed under the terms and conditions of the Creative Commons Attribution license (http://creativecommons.org/licenses/by/3.0/). 